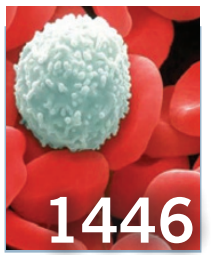

\author{
Blood sort: \\ Drugmakers hedge \\ on promise of \\ targeting CD38
}

\title{
Early-stage therapies target surgery-induced erectile dysfunction
}

This year, around 240,000 men in the US alone will be diagnosed with prostate cancer, and most of them will choose to either surgically remove all or part of the prostate gland or undergo radiation treatment. These therapies can help keep the cancer at bay, but they come at a steep cost in terms of a man's quality of life: more than half of all men who undergo such aggressive procedures are expected to face years of sexual difficulties, owing to inadvertent damage to the cavernous nerves that weave through the pelvis in close proximity to the prostate. "There is nerve trauma in one hundred percent of prostatectomies," says Trinity Bivalacqua, a urologist at the Johns Hopkins University School of Medicine in Baltimore.

Unfortunately, drugs such as Viagra (sildenafil) and Cialis (tadalafil) only boost blood flow to the penis during sexual stimulation and don't alter the underlying nerve signaling. So there's little that these erectile dysfunction pills can do to overcome surgery-induced nerve injury and its consequences on male potency. However, a new generation of neuroprotective drugs or cell therapies given around the time of surgery could one day protect sexual function in prostate cancer survivors.

In late August, at the World Meeting on Sexual Medicine in Chicago, researchers from Spain reported that bone marrow-derived stem cells injected into the base of the penis, combined with oral doses of tadalafil, helped rats nearly completely recover their erectile function after cavernous nerve injury. (Tadalafil had only marginal effects on its own.) At the same conference, a team led by Arthur Burnett, a colleague of Bivalacqua's at Hopkins, presented an animal trial showing benefits from glial growth factor 2 (GGF2), which is involved in the development of the peripheral nervous system. Administration of this cytokine under the skin of rats before and after cavernous nerve damage led to an increase by more than half of intracavernous pressure upon nerve stimulation, one marker of erectile function. In addition, it cut in half the number of denervated cells-lacking the

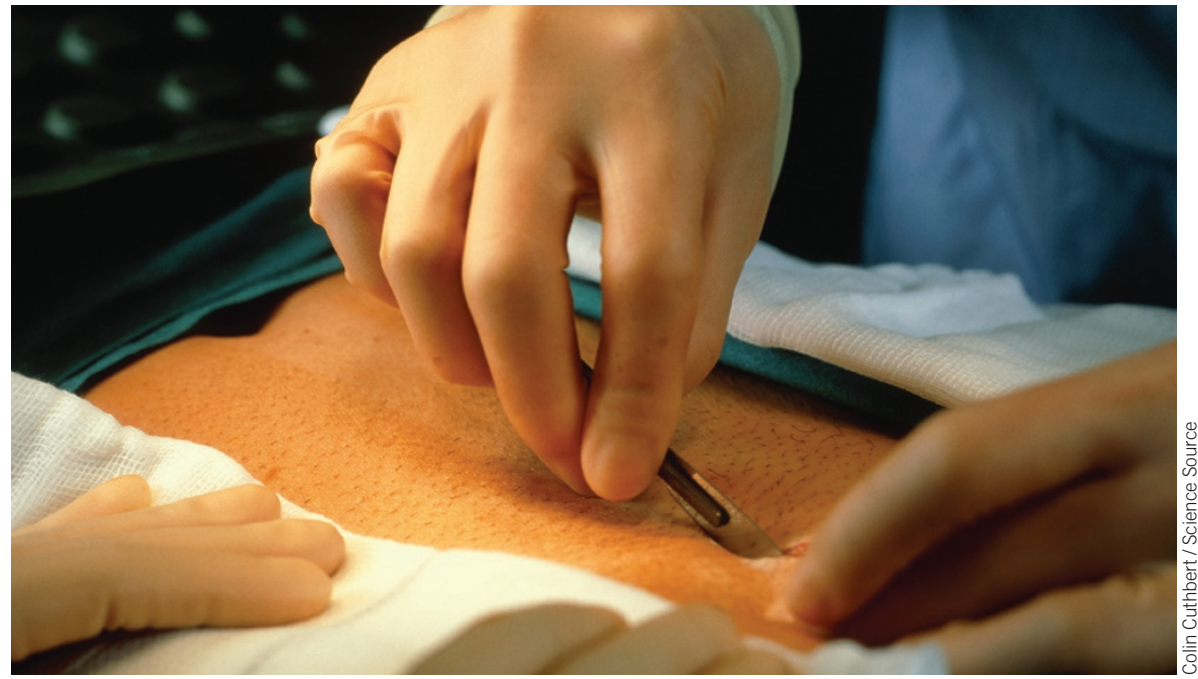

Incisive problem: Prostate surgery can save a man's life, but compromise his potency.

ability to transduce chemical signals-in the cavernous nerve.

GGF2 is currently being evaluated by Acorda Therapeutics of Ardsley, New York, in a 50 -person, phase 1 trial for its ability to restore cardiac muscle contractility following heart failure. If the drug proves safe, the company plans to launch additional preclinical trials evaluating dosage and timing of the drug. They don't yet have a timeline for launching human trials of GGF2 for erectile dysfunction.

\section{It takes nerve}

Additional promising therapeutic strategies have also started to emerge. In April, Burnett reported that treatment with the antiinflammatory molecule annexin-A1 effectively preserved penile function in rats with crushed cavernous nerves, evidently by protecting the penile tissue against fibrotic scarring (BJU Int. doi:10.1111/j.1464-410X.2012.11097.x, 2012). And in May, Carol Podlasek, a neurobiologist at the Northwestern University Feinberg School of Medicine in Chicago, showed last year that rats receiving sonic hedgehog $(\mathrm{SHH})$, a signaling protein known to promote axon growth, through a nanotechnology hydrogel system applied to the cavernous nerve and penis during surgery were protected against damage of both this nerve and its downstream effects on sexual function.

This May at the America Urological Association meeting in Atlanta, Podlasek's team presented data showing that the drug can both be neuroprotective against cavernous nerve degeneration as well as promote neuron regeneration after injury has occurred. They went on to show that $\mathrm{SHH}$ acts through brainderived neurotrophic factor, another protein being studied as a potential therapeutic for nerve injury-induced erectile dysfunction. $\mathrm{SHH}$ is "clearly an essential component in maintaining the morphology of the penile tissue," says Podlasek.

Podlasek and others point out that cavernous nerve injuries occur at a predictable timeduring a scheduled prostate surgery—offering doctors a unique window of opportunity to limit the damage at an early time point. "I think there's a lot more we can do in this case than with a patient who gets into the hospital hours after an [unexpected] injury," says Jeffrey Spees of the University of Vermont in Burlington, who has studied stem cell therapies as a treatment for prostatectomies. "It's just a matter of working out the best therapy."

Sarah C P Williams 